\title{
Comparative Study for Software Project Management Approaches and Change Management in the Project Monitoring \& Controlling
}

\author{
Amira M. Gaber, Sherief Mazen, Ehab E. Hassanein \\ Department of Information System, Faculty of Computer and Information Sciences, Cairo University
}

\begin{abstract}
A software project encounters many changes during the software development life cycle. The key challenge is to control these changes and manage their impact on the project plan, budget, and implementation schedules. A well-developed change control process should assist the project manager and the responsible team in monitoring these changes.In this paper, we examine a number of approaches for project monitoring \& control with different scenarios of project schedules. The comparison shows the effect of applying each approach on the cost and the time of the project. The evaluation illustrates that the integrated software Project and Change Management (IPCM) is a more efficient for providing more control in tracking change requests, and improve the performance monitoring process.
\end{abstract}

Keywords-Software Engineering; Software Project Management; and Software Change Management

\section{INTRODUCTION}

One of the most important processes in developing any software project is project monitoring and control process. It controls the operation of the project according to the project plan. Also, it is one of the CMMI® process areas level 2 [1]. To measure the success of the software development project, the actual and the estimated project plans are compared and analyzed. When the performance of the project is deviated from the actual project plan, the corrective actions will be followed to achieve project success by using analysis result [2].

There are different monitoring approaches for the development of the software project; the first approach is the classic approach, which tracks different baselines on a regular basis of the project to estimate percentages of budget spent, work done and time elapsed [3]. The second approach is The Earned Value Analysis approach (EVA) which compares the planned amount of work with what is actual completed to determine if Cost, Schedule and Work accomplished are proceeding as planned or not. EVA measures the progress of the project by providing consistent numerical indicators, which can be used to evaluate, compare, forecast projects completion dates and final costs, and provide schedule and budget variances along the project [4].

Finally, the proposed Integrated Project and Change Management Framework (IPCM) tracking approach [4], which mainly integrates the activities of both software project management and software change management.

This integration useful for the following points:
1) When a change occurs, it will go through the whole change management process before execution as in Figure 1.

\begin{tabular}{|c|c|c|c|c|}
\hline $\begin{array}{l}\text { 1. Change } \\
\text { identification }\end{array}$ & $\begin{array}{c}\text { 2. Change } \\
\text { Impact evaluation }\end{array}$ & $\begin{array}{l}\text { 3. Change } \\
\text { decision }\end{array}$ & $\begin{array}{c}\text { 4. Change } \\
\text { implementation }\end{array}$ & $\begin{array}{l}\text { 5. Change } \\
\text { request }\end{array}$ \\
\hline
\end{tabular}

Fig. 1. the change management process [5]

2) Managerial reports will be prepared and delivered based on performance and improvements the activities of the project. When the Change Management Team (CMT) checks for the Change Request (CR), The CMT uses an Employee performance sheet for each $C R$ responsible according to the completion date of the related $C R$ (i.e. early $C R$ means the responsible person will be rewarded; otherwise punished).

3) Providing an accurate Time Accumulator (TA) to record any CRs finished earlier than planned which will result in revising the project plan or any delayed CRs that will assist the next level of taking decisions to take corrective actions to the project plan.

4) Helping the higher level of management for better decision making in case of any budget deficit or surplus by using the Cost Accumulator (CA) to monitor the expenditures of the project plan.

5) Notifying the higher level of management in case of any possibility of early project completion, which might result in the revision of the operational processes that depend on the deadline of the project.

In the first two approaches, there is no integration and synchronization between software project management and change management. The change management must address in the project plan for:

- Including the procedure for handling Scope and variance changes.

- Creating forms to record and evaluate Change requests.

- Identifying the revision and approval Processes for changes.

- Adjusting the Change process to the Current plan.

- Avoiding the problem of unrecognized changes as team members may decide to add scope items to improve the final product, and don't realize the added cost or time that will be incurred during execution. Therefore, ignoring to monitor the changed scope items 
will definitely have an effect on the time and cost of the project.

So, the change management process should be used to allocate and evaluate changes before execution. When approved a change, the budget for the affected work package is modified [6].

This paper focuses on the project monitoring and control process area. This process area provides an understanding of the project's progress so that appropriate corrective actions can be taken in case of:

- The performance of the project deviates from the project plan.

- The project takes more time or cost or both than planned.

- The scope changes are not controlled which will affect the project schedule and budget. An effective change control process will help the project manager and team for managing the scope changes.

Also, we will compare the first two approaches with the Integrated Project and Change Management Framework (IPCM) approach during the project monitoring and controlling phase for the following purposes:

- Managing the whole software project and its change requests.

- Facilitating the distribution of tasks (change requests) and the availability of information about each change request

- Providing more control over the project by solving most of the technical issues instead of all of them reaches to management.Reporting the status of time and cost using accumulators to the management to take corrective actions.

The rest of paper we will evaluate each monitoring approach and shows its impact on the efficiency of the project with different schedule scenarios that might occur along the project life cycle.

\section{RELATED WORK}

\section{$\rightarrow$ Monitoring Approaches}

\section{A. The Classic Approach}

After planning the project and building the project network, with each task assigned an estimated duration (start and end dates) and an estimated cost. The project manager starts with a baseline project schedule which remains fixed and never to be used during the project lifetime.

It is only used for comparison against other project schedules to check if tasks are executed according to the given schedule or not. The baseline project schedule can also be used to evaluate the project cost against the estimated budget. The project monitoring and controlling cycle is shown in Fig 2 [7].

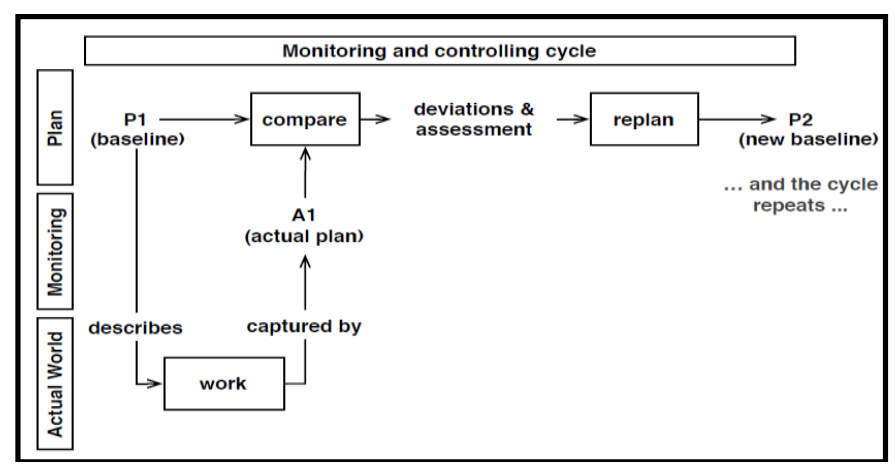

Fig. 2. Project Monitoring and Controlling Cycle [7]

\section{B. The Earned Value Analysis (EVA) Approach}

Earned Value Analysis (EVA) is a project management approach used to measure the project's progress in an objective manner. According to the Project Management Institute (PMI) [8] EVA provides an early warning of performance problems. Referring to EVA as EV (Earned Value) most often, the EV measures the project performance and the project progress by efficiently integrating the management of the three most important elements in a project; cost, schedule and scope. In fact, it calculates the cost and time performance indices of a project, estimates the completion cost and the completion time of a project, and measures the performance and the progress of a project by comparing the planned value and the actual costs of activities to their corresponding earned values [9].

\section{EVA is used to}

- Provide an integrated view of the project by measuring planned cost, earned value, and actual costs in terms of monetary values.

- Calculate schedule variance. A negative variance means that the project is behind schedule.

- Calculate cost variance. A negative variance means that the project is over budget.

- Calculate Cost Performance Index (CPI) that measures the amount of accomplished physical work against the money spent to accomplish that work.

$\circ \mathrm{CPI}>1$, project is efficient

$\circ \mathrm{CPI}<1$, project is inefficient

- Calculate Schedule Performance Index (SPI) that measures the amount of accomplished physical work against the amount of scheduled work.

- $\mathrm{SPI}>1$, project is ahead of schedule

○ $\mathrm{SPI}<1$, project is behind schedule

- Earned Value Computation

- 50/50 Rule (50\% of planned value at start and 50\% at end)

- 20/80 Rule (20\% at start and $80 \%$ at end)

- 0/100 Rule (0\% at start and $100 \%$ at end)[7]

Fig 3 shows the EVA Graph displaying cost cumulative curves: Actual, Planned, and Earned. 


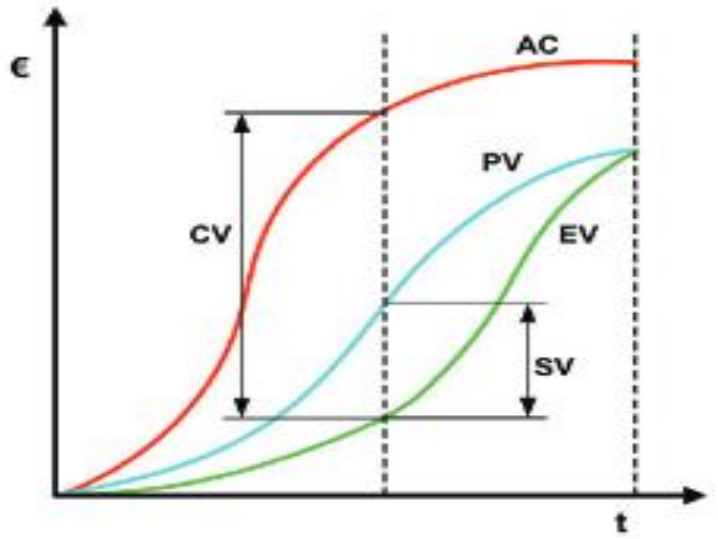

Fig. 3. Earned Value Analysis Graph [10]

\section{The Integrated Project and Change Management (IPCM) Approach}

The Integrated Project and Change Management (IPCM) approach integrates the activities of change management and project management as shown in Figure 4. It treats each task as a Change Request (CR). A Change Request (CR) is a formal proposal for an alteration associated with a task in the project plan. CR Types includes: Add Requirement, Update Requirement, Delete Requirement, New Version, and New Release [11]. IPCM provides an accumulation of resources in terms of time and cost using the Time Accumulator (TA), and the Cost Accumulator (CA). IPCM is used as an indicator to the status of the project plan in term of saved time and cost. Time Accumulator (TA) uses the following equation:

$T A_{n}=T A_{n-1}+$ Estimated time $(E T)_{n}-$ Actual Time $(A T)_{n}$ And Cost Accumulator (CA) uses:

$C A_{n}=C A_{n-1}+$ Estimated cost $(E S)_{n}-$ Actual cost $(A C)_{n}$

In addition, the IPCM Tracks change requests, and if there is any delayed or early finished tasks, then CMT will know who is responsible for that and put them in the project tracking performance sheet for either punishment or reward [4].

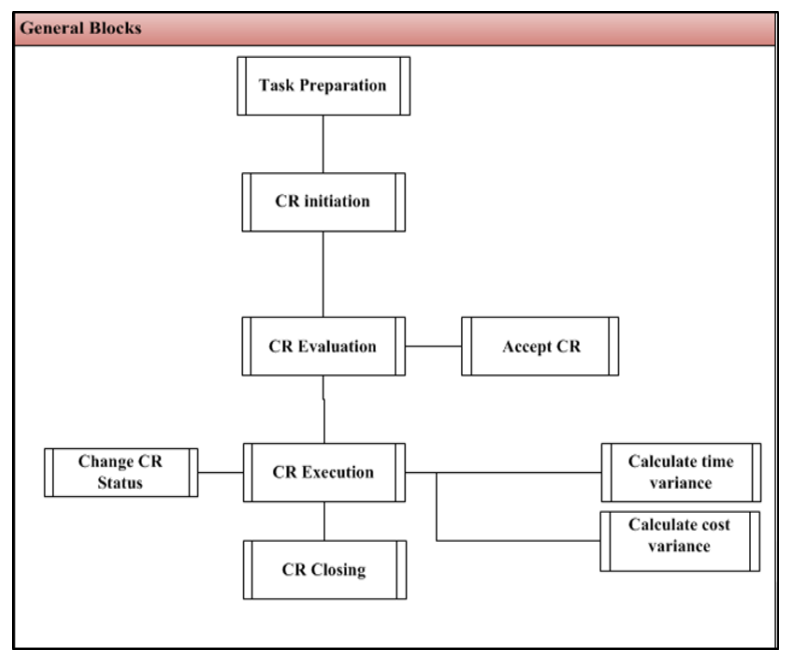

Fig. 4. The Overall Components of the Integrated Framework

\section{IPCM FRAMEWORK EVALUATION}

The IPCM Framework Evaluation is based on five possible scenarios that can occur along the project life cycle. A comparison and an evaluation are made between the different monitoring approaches in terms of both the cost and the time of the project for each of the possible scenarios.

Scenario 1: Some CRs on critical path finish earlier than planned

In this scenario, the project will be affected $\&$ finish earlier than the scheduled completion date.

Scenario 2: Some CRs on critical path finish earlier than planned and appear on another critical path

In this scenario, the project will be affected $\&$ finish earlier than the scheduled completion date. The affected CRs may appear on another critical path as a result of the early finish, thus the PM is responsible to revise the project plan and recalculate the critical path

Scenario 3: Some CRs on critical path finish later than planned, but within the contingency plan of the project

In this scenario, the PM determines the allowable delay time in the schedule that won't affect the project completion date. The allowable delay time should be defined in the contingency plan of the project. The PM checks if the delay is within the contingency plan or not.

Scenario 4: Some CRs on critical path finish later than planned, but not within the contingency plan of the project

In this scenario, the PM determines the allowable delay time in the schedule that won't affect the project completion date. The allowable delay time should be defined in the contingency plan of the project. The PM considers the delay in case of violation of the contingency plan.

Scenario 5: Some CRs finish later than planned, and don't affect the scheduled completion date.

Figure 4 and 5 show the network diagram and Gantt chart for a project consisting of 8 tasks. The project's start date is 03 December, 2014 and the completion date is 13 January, 2015 and the calculated critical path is A-B-D-E-G-H 


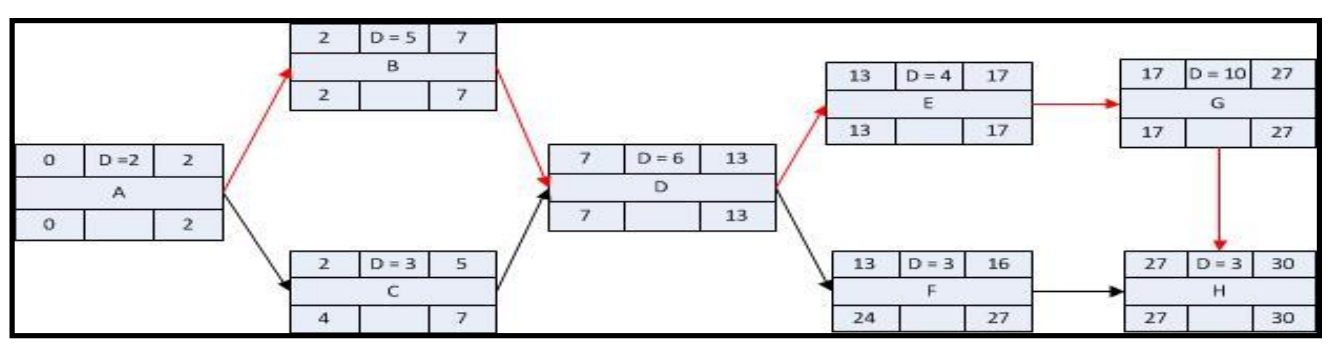

Fig. 5. Project Network Diagram

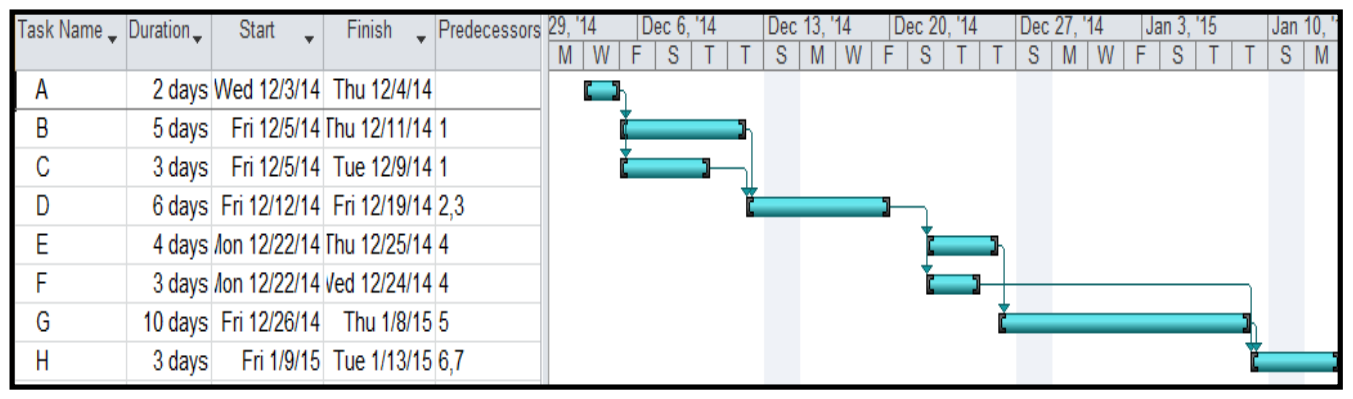

Fig. 6. Project Gantt Chart

For these scenarios, this is the estimated and actual times for the tasks on the critical path and its Time accumulator for

each scenario.

TABle I. The Time Accumalator, Estimated Time and Actual Time for All Tasks for All Scenarios

\begin{tabular}{|c|c|c|c|c|c|c|c|c|c|c|c|}
\hline \multirow[b]{2}{*}{$\begin{array}{l}\text { Task } \\
\text { (CRs) } \\
\end{array}$} & \multirow[b]{2}{*}{$\begin{array}{l}\text { (ET) } \\
* \\
\end{array}$} & \multicolumn{2}{|r|}{ Scenario1 } & \multicolumn{2}{|c|}{ Scenario2 } & \multicolumn{2}{|c|}{ Scenario3 } & \multicolumn{2}{|c|}{ Scenario4 } & \multicolumn{2}{|c|}{ Scenario5 } \\
\hline & & $\begin{array}{l}\text { (AT) } \\
* *\end{array}$ & $\begin{array}{l}\text { (TA) } \\
* * *\end{array}$ & $\begin{array}{l}\text { (AT) } \\
* *\end{array}$ & $\begin{array}{l}\text { (TA) } \\
* * *\end{array}$ & $\begin{array}{l}\text { (AT) } \\
* *\end{array}$ & $\begin{array}{l}\text { (TA) } \\
* * *\end{array}$ & $\begin{array}{l}\text { (AT) } \\
* *\end{array}$ & $\begin{array}{l}\text { (TA) } \\
* * *\end{array}$ & $\begin{array}{l}\text { (AT) } \\
* *\end{array}$ & $\begin{array}{l}\text { (TA) } \\
* * *\end{array}$ \\
\hline $\mathrm{A}$ & 2 & 1 & 1 & 2 & 0 & 3 & -1 & 1 & 1 & 3 & -1 \\
\hline $\mathrm{B}$ & 5 & 5 & 1 & 1 & 4 & 6 & -2 & 7 & -2 & 10 & -4 \\
\hline $\mathrm{D}$ & 6 & 3 & 4 & 6 & 4 & 7 & -3 & 7 & -3 & 4 & -2 \\
\hline $\mathrm{E}$ & 4 & 2 & 6 & 2 & 6 & 5 & -4 & 8 & -6 & 10 & -4 \\
\hline $\mathrm{G}$ & 10 & 8 & 8 & 5 & 11 & 11 & -5 & 15 & -11 & 4 & 2 \\
\hline $\mathrm{H}$ & 3 & 3 & 8 & 3 & 11 & 4 & -6 & 11 & -19 & 3 & 2 \\
\hline
\end{tabular}

\section{A. The Classic Approach}

\section{1) Scenario 1}

As a result from the actual and the estimated time of this scenario, the PM has no clue about the tasks that finish earlier than planned. From the given table above, one day is saved for task A, 3 days for task D, 2 days for task E and 2 days for task G. The saved 8 days are not used to accelerate any tasks in the project, and the project ends up at the scheduled completion date.

\section{2) Scenario 2}

As a result from the actual and the estimated time of this scenario, the recalculation of the critical path is not regularly supported. Figure 6 shows the new recalculated critical path that needs to be monitored by the PM.

\section{3) Scenario 3, 4:}

As a result from the actual and the estimated time of this scenario, the PM checks the contingency plan and takes any necessary corrective actions.
4) Scenario 5:

As a result from the actual and the estimated time of this scenario, the PM monitors each task at the end of its delivery, and takes corrective actions to avoid any delay of the scheduled completion date.

In the classic approach, the PM has no information about the tasks that finish earlier than planned. Therefore, the resources of the project (saved time and cost) are not utilized efficiently, and can't be used to affect other tasks.

\section{B. The IPCM Approach}

In this approach, the Change Management Team (CMT) tracks the actual time against the planned time for each CR after execution. The decision making depends on the numeric results generated by the Time Accumulator for all the CRs [4].

\section{1) Scenario 1:}

According to Equation (1); tasks A, D, E and G finished earlier than their due dates: the time accumulator for task A is 1 day which means that the PM is alerted by the CMT to re- 
vise the project plan and start the next CR 1 day earlier than planned. The TA for tasks B and D are 1 and 4 , then the PM starts the next CR 4 days earlier than planned. In the same way, tasks $\mathrm{E}$, and $\mathrm{G}$ result in starting next CRs by 6 and 8 days earlier than the planned start dates. At the end, the project finishes 8 days earlier than planned.

\section{2) Scenario 2}

According to Equation (1); tasks B, E, G and $\mathrm{H}$ finished earlier than their due dates: the TA for task $\mathrm{B}$ is 4 days which means that the PM is alerted by the CMT to revise the project plan and start the next CR 4 days earlier than planned. In the same way, tasks E, and $\mathrm{G}$ result in starting the next CR 11 days earlier. The CMT detects that task F deviates from the estimated time by 6 days $(3-9=-6)$ which leads to a change of the critical path. Therefore, The CMT asks the PM to revise the project plan and recalculate the critical path. At the end, the project finishes 11 days earlier than planned with a new critical path (A-B-D-F-H).

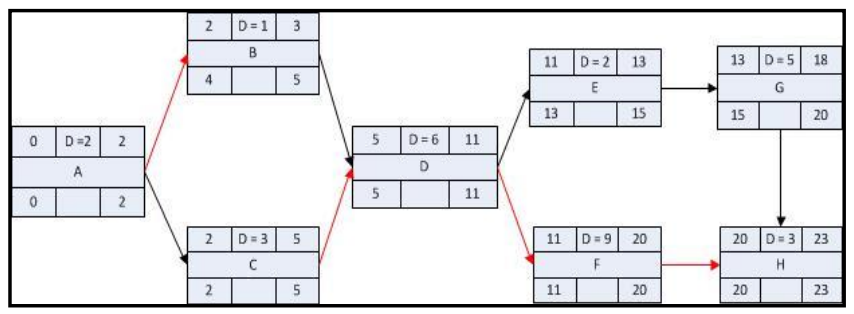

Fig. 7. Gantt Chart for the Recalculated Critical Path

\section{3) Scenario 3}

According to Equation (1); tasks A,B,D, E, G and $\mathrm{H}$ are delayed than planned: the TA for tasks A, B, D, E, G and $\mathrm{H}$ are $-1,-2,-3,-4,-5,-6$, and the CMT alerts the PM since the first delayed task (task $\mathrm{A}$ in the given example). In case of a delay, the PM checks the contingency plan to take corrective actions or raise the issue to a higher level of management. At the end, the project is delayed 6 days after the original plan with no violation to the contingency plan.

\section{4) Scenario 4}

According to Equation (1); tasks A, B, D, E, G and H are delayed than scheduled: the TA for tasks A, B, D, E, G and $\mathrm{H}$ are $1,-2,-3,-6,-11,-19$, and the CMT alerts the PM since the first delayed task. In case of a delay, the PM checks the contingency plan if the delays are within range or not to take corrective actions or raise the issue to a higher level of management. In the given example, the project is delayed 19 days from the original plan which violates the contingency plan.

\section{5) Scenario 5}

According to Equation (1); tasks A,B, D, E, G and $\mathrm{H}$ are delayed after their due dates: the TA for tasks A, B, D, E, G and $\mathrm{H}$ are $-1,-4,-2,-4,2,2$. Using the TA for all tasks, the project is not delayed, and the delayed tasks can borrow some time from the predecessor tasks that finish earlier than their due dates. Therefore, tasks can be delayed from their planned due dates without affecting the whole project. In this scenario, the IPCM approach takes advantage of the accumulated time and cost to accelerate the delayed CRs. This advantage is unique to this approach that can help crashing the project.
In the IPCM approach, tracking the saved time after executing each CR leads to several advantages. One advantage is that accurate estimation of both the cost and time variances of the project. Another benefit is that tasks can finish earlier than planned. It is important to note that the CMT puts everyone responsible for accomplishing a task in the project tracking performance sheet for further punishment or reward.

\section{The Earned Value Analysis Approach}

In this approach, the PM uses a suitable rule to calculate "\% complete" of each task [7]. There are three rules to do that: first; $50 \%-50 \%$ rule; the PM grants $50 \%$ of the time to the actual start date and the task remains marked as " $50 \%$ completed" until an actual finish is recognized when the remaining $50 \%$ is granted and the task become " $100 \%$ completed". Second; $20 \%-80 \%$ rule; the PM grants $20 \%$ of the time to the actual start date with the remaining $80 \%$ granted at the actual finish of the task. Third; $0 \%-100 \%$ rule; grants nothing until the work package is $100 \%$ completed.

\section{1) Scenario 1}

The PM uses the suitable rule to be applied on the given case. Regardless of the applied rule, the EVA calculates the Schedule Performance Index (SPI) based on how far the project is ahead of the schedule. So, the EVA detects an early finish based on applying the suitable rule.

\section{2) Scenario 2}

The PM uses the suitable rule to be applied on the given case. Regardless of the applied rule, the EVA calculates the Schedule Performance Index (SPI) based on how far the project is ahead of the schedule. In this scenario, the PM is not aware of any emerging critical paths. Therefore, the EVA detects an early finish based on applying the suitable rule without recalculating of the critical path.

\section{3) Scenario 3, 4}

The PM uses the suitable rule to be applied on the given case. Regardless of the applied rule, the EVA calculates the Schedule Performance Index (SPI) based on how far the project is ahead of the schedule. The EVA approach may give better prediction than the IPCM approach in case if tasks will be delayed before completion, but this depends on the applied rule. In the IPCM approach, it predicts the delay of the tasks after completion. In addition, the IPCM approach calculates the actual delay more accurately than the EVA approach. The IPCM approach solves the delay problem by dividing the MCR into sub CRs that can be controlled and executed in parallel. It is important to note that no awareness of the contingency plan is available to be checked by the PM.

\section{4) Scenario 5}

The tasks can be delayed without affecting the whole project. The IPCM approach gives the advantage to accumulate the time and cost to give the delayed CRs extra time and cost from the accumulators to accomplish and recover the delay. This advantage can help the project in crashing. This scenario is not supported in both the classic and EVA approaches.

The EVA approach is better than the classic approach in tracking changes along the project. EVA can provide indices to improve the oversight of the project, and is better than the 
IPCM approach in the early prediction of any possibility of an early completion of any task. EVA has the disadvantage of not using the change management process along the project [6] while the IPCM approach provides index variables to monitor the project, and integrates the change management and project activities.

\section{CONCLUSION}

In this paper, we made a comparison between the classic approach, the IPCM approach and the EVA approach. The comparison proved that to improve the project monitoring and controlling phases, the change management and project management activities should be integrated. The IPCM Framework Evaluation of the comparison has different perspectives:

\section{A. From the tasks perspective}

The IPCM approach deals with each task as a Change Request (CR) and integrates the $\mathrm{CR}$ with the change management process. On the other hand, the classic and the EVA approaches are not well defined the CR procedure.

\section{B. From the quality perspective}

The IPCM approach only integrates the software project and change management activities to achieve the quality. However, the EVA and the classic approaches don't include any quality guidelines within the project.

\section{From the project resources perspective}

The IPCM approach effectively utilizes the project resources while the EVA approach does partial utilization and no utilization at all in the classic approach.

\section{From the time perspective}

The IPCM approach monitors all tasks or CRs along the project after completion dates and gives accurate values for any deviations from the project schedule. On the other hand, the classic approach monitors the project as baselines on regular basis. However, the EVA monitors the project based on rules: $0-100 \%$ or $20-80 \%$ or $50-50 \%$, which determine if the project is ahead or behind schedule.

\section{E. From the cost perspective}

The IPCM approach monitors all tasks or CRs along the project after completion dates and give accurate values for any cost deviations.

The classical approach monitors the project as baselines on regular basis with respect to the estimated and actual costs, but depends on the experience of the project while the EVA Approach controls the project on some basis rules which determine if the project needs to be recovered or not.

\section{FUTEURE WORK}

There are some open problems are mentioned below to be considered in future:

- The CMT alerts the project manager to revise the project plan and recalculate the critical path when a change occurs. A simple enhancement can be done by avoiding the recalculation of the critical path from scratch because it is a waste of time. The recalculation should only include activities with a change in duration, which can be found by doing a simple time intersection of the project activities.

- The framework can be extended to take into consideration the people side of the project in the same way taken by the ADKAR Model in order to maximize the profit of the integration.

- The proposed framework works along the development phase only. An interesting point to consider is to extend the framework to study the maintenance phase activities after software delivery.

\section{REFERENCES}

[1] CMU/SEI, "Capability Maturity Model Integration,CMMI for Development, Version 1.3”, CMU/SEI-2010 RT-033, Pittsburgh, Software Engineering Institute Carnegie Mellon University, 2010.

[2] Sunart Wanapaisan, Taratip Suwannasart, and Apinporn Methawachananont ," An Approach for Monitoring Software Development Using Timesheet and Project Plan"Proceedings of the International MultiConference of Engineers and Computer Scientists 2013 Vol I, IMECS 2013, March 13 - 15, 2013, Hong Kong

[3] Malte Foegen," Project Management 08 - Project Monitoring and Control", wibas IT Maturity Services GmbH @ 2007

[4] Amira M. Gaber, Sherif Mazen, Ehab E.Hassanein,"Framework for Integrating Software Project Tasks and Change Requests ", International Journal of Computer Applications (0975 - 8887) Volume 125 - No.12, September 2015

[5] Henri Elemo," DEFINING SOFTWARE CONFIGURATION MANAGEMENT FOR PRODUCT DEVELOPMENT ", May 30, 2008

[6] Joseph A Lukas," Earned Value Analysis -Why it Doesn't Work", AACE INTERNATIONAL TRANSACTIONS, 2008

[7] Ursula Kuehn, EVP," Earned Value Management - Why Am I Being Forced to Do It ?", AACE International Transactions, 2007

[8] Anbari, F., "Earned value project management method and extensions", Project Management Journal, volume 34, issue (4), 2003, P.12-23.

[9] Leila Moslemi Naeni, Shahram Shadrokh, Amir Salehipour," A fuzzy approach for the earned value management ", International Journal of Project Management, Volume 32, Issue 4, May 2014, Pages 709-716

[10] Fernando Acebes, Javier Pajares, José Manuel Galán, Adolfo LópezParedes," Beyond Earned Value Management: A Graphical Framework for Integrated Cost, Schedule and Risk Monitoring ", Procedia - Social and Behavioral Sciences volume 74, (2013), P. 181 - 189

[11] A. R. M. Nordin, S. Suhailan, "Managing Software Change Request Process: Temporal Data Approach "International Journal of Computer Science and Security, (IJCSS) Volume (3), Issue (3), 2009 